\title{
A arte de ter razão
}

The art of being right

\author{
Sílvia Faustino de Assis Saes \\ Professora do Departamento de Filosofia e do \\ Programa de Pós-Graduação em Filosofia da UFBA \\ E-mail: silviassisaes@gmail.com
}

Resumo: Este artigo pretende mostrar de que maneira a "dialética erística", que Schopenhauer define como "a arte de ter razão", surge da combinação de duas linhas de pensamento sobre a dialética: a tradição aristotélica, que concebe a dialética como um discurso argumentativo baseado em opiniões geralmente aceitas; e aquela, inaugurada por Kant, que concebe a dialética como uma lógica das aparências ou lógica da ilusão. Este trabalho argumentará a favor da seguinte interpretação: ao absorver e tentar superar os ensinamentos de ambas as tradições, Schopenhauer acaba produzindo os rudimentos de uma espécie de racionalidade comunicativa na qual o funcionamento polêmico da linguagem, concebida como instrumento eficaz de certa "vontade de poder", torna-se o único responsável pela consolidação das crenças e valores sociais.

Palavras-chave: Schopenhauer; Dialética; Keywords: Schopenhauer; Dialectic; Eristic.

Abstract: This paper intends to show how Schopenhauer's 'eristic dialectics', defined by him as 'the art of being right', arise from the combination of two lines of thought on dialectics: the Aristotelian tradition, in which dialects are understood as an argumentative discourse based on generally accepted notions; and the tradition set in motion by Kant, which understands dialectics as a logic of appearances or of illusion. The interpretation we favor, and which we intend to argue in this work, is the following: while attempting to assimilate and to go beyond the teachings of both traditions, Schopenhauer sets forth the basic elements of a kind of communicative rationality in which the polemical functioning of language, understood as the effective instrument of a certain 'will of power', becomes the sole factor which determines the consolidation of social beliefs and values.

Erística 
arte de ter razão é o título que Franco Volpi dá ao pequeno tratado
que Schopenhauer produz em Berlim, por volta de 1830-1831, um
manuscrito jamais publicado pelo filósofo'. O título escolhido por Volpi não poderia ser mais apropriado, já que o tema essencial das páginas compostas pelo texto, pelos adendos e notas é justamente o de revisar o antigo conceito de dialética, a fim de reconceituá-la como uma "arte de ter razão", isto é, como "dialética erística". Uma pergunta simples constitui o ponto de partida deste trabalho: que espécie de relação conceitual o texto mantém entre a faculdade da "razão" [Vernunft] e a "arte de ter razão" [die Kunst Recht zu behalten ou Rechthaben] $]^{2}$ ? Para bem formular essa questão é crucial entender que o conceito schopenhaueriano de dialética erística se constrói na intersecção entre duas tradições de pensamento sobre a dialética: a linha que remonta à visão aristotélica da dialética como um método de argumentar a partir de opiniões geralmente aceitas; e a linha, inaugurada por Kant, que concebe a dialética como uma lógica das aparências ou lógica da ilusão. Pois, se "é com Kant", como diz Gérard Lebrun, "que o idealismo alemão aprende a pensar a razão no regime da dialética e da erística"3, por outro lado, é com o conceito de dialética em Aristóteles que Schopenhauer parece querer acertar as contas. De fato, a referência a Kant e à sua concepção da dialética como "lógica das aparências" não passa de uma breve menção, além de ser feita em claro tom de crítica. Ao criticar Aristóteles e mencionar criticamente a concepção de Kant, Schopenhauer deixa claro que seguirá a rota de um desvio em relação a ambas as tradições. Mas apesar de sinalizar claramente essa posição intermediária e singular entre Aristóteles e Kant, o denso texto é muito curto e oferece poucas indicações para aprofundamentos. Não obstante isso, como o próprio Volpi reconhece ${ }^{4}$, o texto apresenta o vínculo essencial do conceito de dialética com a própria condição humana de um ser dotado de linguagem, sendo isso o que torna esse escrito atual. Pode-se acrescentar essa observação dizendo que ele se mostra adequadamente pertinente a muitas preocupações teóricas que hoje em dia a filosofia dedica às nossas práticas linguísticas. Nesse sentido creio ser

1 Cf. SCHOPENHAUER, A. A arte de ter razão. Organização e ensaio de Franco Volpi, São Paulo: Martins Fontes, 2005. Texto original consultado: Eristische Dialektik. In: Schopenhauer in Kontext (Werke auf CD-ROM), Kap. 446, VI 393 - VI 428.

2 Na língua portuguesa e demais línguas latinas a expressão "ter razão" (que traduz o termo alemão "Rechthaben") contém a mesma palavra que designa a faculdade da "razão" (que corresponde ao termo alemão "Vernunft").

3 LEBRUN, G. A dialética pacificadora, p. 110.

4 VOLPI, F. Schopenhauer e a dialética, p. 114. 
possível distinguir, no pequeno texto de Schopenhauer, os rudimentos de uma espécie de "racionalidade" comunicativa na qual a linguagem, escapando das leis abstratas da razão [Vernunft] se revela como o instrumento eficaz de certa "vontade de poder". Esta seria a mola propulsora de uma polis discursiva em seu incessante (e frágil) processo de construção. Expor essa hipótese de leitura e entender essa "arte" - Kunst - contrailuminista de "ter razão" [Rechthaben] a despeito de possuir a razão [Vernunft] como faculdade, é o principal objetivo deste trabalho.

Para tudo o que se segue, será útil lembrar que a concepção aristotélica da dialética se encontra intrinsecamente ligada à busca de certo método de raciocinar, conforme atesta o início dos Tópicos:

O objetivo desta exposição é encontrar um método que permita raciocinar sobre todo e qualquer problema proposto, a partir de proposições geralmente aceites, e bem assim defender um argumento sem nada dizer de contraditório ${ }^{5}$.

Trata-se, pois, de uma atividade argumentativa de amplíssima aplicação, que toma proposições geralmente aceitas [endoxa] como base e se processa de modo a evitar a contradição. Definindo a dialética aristotélica como uma "forma de racionalidade" inscrita em situações concretas de diálogo ou discussão, Enrico Berti a caracteriza como "a mais típica práxis humana" condição e que, nas mãos de Aristóteles, se converte em disciplina quando ele expõe o modo técnico de exercitá-la. Segundo este estudioso, os elementos fundamentais da atividade descrita por Aristóteles são os seguintes: i) o "perguntar", que envolve tanto a pergunta inicial, que indaga sobre a essência com finalidade cognitiva, como também as perguntas que se sucedem no processo de obtenção das premissas; ii) o "argumentar", isto é, o deduzir conclusões de premissas, segundo as regras apresentadas na analítica; iii) e a "contradição", à qual um dos interlocutores busca conduzir o outro, e que este outro procura evitar ${ }^{7}$. Signo de falsidade, a contradição anula qualquer tese e torna-se critério crucial quer para estabelecer, quer para refutar uma proposição ou argumento. Quem quer estabelecer uma tese deve evitá-la a todo custo; quem quer derrubar uma tese deve

5 ARISTÓTELES. Tópicos, i, 1, 100 a, p. 233.

6 BERTI, E. As razões de Aristóteles, p. 19.

7 Idem, pp. 21-22. 
levar quem a defende a cair numa contradição.

Há, no entanto, uma regra fundamental que os interlocutores têm de respeitar e sem a qual a discussão dialética se reduziria à mera justaposição de posições opostas: os interlocutores devem concordar com certas premissas, que expressam "opiniões geralmente aceitas" ("endoxa"), e que não podem deixar de ser concedidas. Quando Aristóteles chama de "dialético" o raciocínio obtido a partir de premissas que expressam opiniões geralmente aceitas, ele as define em contraste com as premissas dos argumentos demonstrativos, que possuem uma certeza evidente, são "verdadeiras e primordiais" e merecem crédito "por si mesmas". Em contrapartida, as premissas dos argumentos dialéticos, que são as proposições que expressam opiniões geralmente aceitas, são apresentadas deste modo: “(...) são fundadas na opinião comum aquelas proposições que parecem credíveis a todos, ou à maioria, ou aos sábios; ou ainda, de entre estes, a todos, à maioria ou aos mais conhecedores e reputados"9.

Longe de serem meras opiniões, as proposições geralmente aceitas envolvem tanto a sabedoria popular quanto a dos filósofos e dos especialistas mais autorizados. Sua "verdade" - quando se admite que expressam alguma - deve-se, não à correspondência com a realidade, mas ao fato de serem admitidas, compartilhadas e reconhecidas por todos. Uma proposição geralmente aceita é "verdadeira" quando corresponde a um sólido acordo de opiniões.

Ora, quando define "dialética erística", Schopenhauer deixa claro que se desvia da concepção aristotélica, que distinguia claramente a dialética da erística. Com efeito, para o autor dos Tópicos, a dialética concerne tão somente às opiniões que real e efetivamente são em geral aceitas, enquanto que a erística envolve o trato com opiniões que meramente aparentam ser geralmente aceitas, sendo por isso que o raciocínio erístico resulta em mera aparência. Aristóteles define o raciocínio erístico nos seguintes termos:

Diz-se raciocínio erístico aquele que resulta de proposições que parecem geralmente ser aceites sem que o sejam, bem como o que decorre, ou parece decorrer, de proposições geralmente aceites, pois nem tudo o que parece fundado na opinião o é de fato. Nem todas as proposições tidas por geralmente aceites se apresentam como

8 ARISTÓTELES. Tópicos, I, 1, 100 b, p. 233.

9 Idem, p. 234 
perfeitamente evidentes, conforme sucede no caso das premissas de base dos raciocínios erísticos; no caso destes, de fato, a sua natureza enganadora é imediatamente evidente quase sempre para quem é capaz de reparar mesmo em pequenos pormenores ${ }^{10}$.

Assim, para Aristóteles, a erística define o raciocínio que parte de opiniões que parecem - mas não são - geralmente aceitas. Mas, diferentemente das opiniões que realmente ou efetivamente são geralmente aceitas, as endoxa meramente aparentes ostentam sua natureza enganadora de modo claramente visível, e a ilusão que envolvem torna-se imediatamente evidente. Ao unificar dialética e erística, Schopenhauer cancela, no âmbito das opiniões, a distinção entre o caráter evidente e o não-evidente de sua ampla aceitação, e toda opinião passa a incorporar a ambivalência do ser e do meramente parecer ser geralmente aceita, não havendo mais como separar nitidamente as modalidades discursivas, como queria Aristóteles. Assim, ele declara que, quanto às endoxa, "não há nada que determine que sejam falsas, tampouco que sejam, (em si e por si) verdadeiras, uma vez que tal fator não é importante"11. Diferentemente de Aristóteles, Schopenhauer parece atribuir o caráter erístico à natureza de toda opinião geralmente aceita. Toda dialética é também erística porque não há critério suficiente para separar, no reino pantanoso em que se movem as opiniões, aquelas que são e aquelas que somente aparentam ser geralmente aceitas. Eis o motivo de dizer que a dialética nada mais é que a "arte de alcançar a aparência da verdade"12, e de disputar de tal maneira que se fique com a razão, seja "com meios lícitos", seja com "ilícitos" (per fas et nefas)".

Ora, se para Schopenhauer a condição de possibilidade e o limite da dialética erística está em alcançar a "aparência da verdade", não estaria ele simplesmente subscrevendo a concepção kantiana da dialética? Embora não apresente claramente a resposta a essa pergunta, o curto texto schopenhaueriano nos autoriza, contudo, a formulá-la. Reportemo-nos ao único momento em que, mesmo sem ter seu nome mencionado, Kant é claramente evocado e acusado de erro:

Esta última [a dialética] foi definida como a lógica das aparências: é falso porque, nesse caso, ela teria utilidade apenas na defesa de proposições falsas. No entanto, mesmo quando se tem razão, a

10 Idem, 100 b - 101 a, p. 234.

11 SCHOPENHAUER, A. A arte de ter razão, p. 61 (nota 2). Na edição original consultada, as notas se encontram no final do texto, após a página VI 428

12 Idem, ibidem.

13 Idem, p. 3. Na edição original, página VI 395 (doravante, a numeração do texto original será: “VI 395”). 
dialética é necessária para defendê-la e deve-se conhecer os estratagemas desonestos para poder enfrentá-los $(\ldots)^{14}$.

A censura feita a Kant corre o risco de permanecer inteiramente enigmática, mas é preciso aceitar o desafio de enfrentá-la se quisermos compreender o próprio ponto de vista de Schopenhauer. Segundo Franco Volpi, a crítica de Schopenhauer "contesta apenas o significado exterior do termo "aparências" (Schein), não o que na realidade Kant entende..."15. Esse significado exterior e negativo coincidiria com a visão da dialética como uma "arte ilusória", que Kant acolhe em seu sistema tãosomente como meio de destruir as ilusões da razão quando, ultrapassando os limites da experiência possível, aspira conhecer os conteúdos correspondentes às ideias da alma, do mundo e de Deus ${ }^{16}$. Para Volpi, Schopenhauer teria deixado de considerar o "significado positivo" da dialética que, em Kant, acaba sendo útil como "crítica da ilusão dialética"17, isto é, como método que permite investigar, desvendar, desmascarar as premissas e as inferências injustificáveis produzidas por toda a metafísica dogmática tradicional, que se denuncia nos seus resultados na forma de paralogismos e antinomias.

De fato, para Schopenhauer, resulta particularmente importante a visão negativa da concepção kantiana. É de Kant que vem a ênfase de que, entre "os antigos",

... a dialética era apenas uma lógica da aparência, uma arte sofística de dar um verniz de verdade à ignorância, e até às suas próprias ilusões voluntárias, imitando o método de profundidade que a lógica geral prescreve e utilizando seus tópicos para embelezar todas as suas alegações vazias ${ }^{18}$.

É claro que, assimilada completamente à arte sofística, a dialética é vista por Kant como o poder de, pelo discurso, produzir a ilusão (de conhecimento) a partir da mera aparência. Entretanto, quando Schopenhauer critica Kant pelo fato de ele ter reduzido a "utilidade" da dialética à mera "defesa de proposições falsas [falscher Sätze]", ele a defende como necessária para também fazer valer uma proposição verdadeira. Pois ele diz: “...mesmo quando se tem razão [Recht hat], a dialética é

\footnotetext{
14 Idem, p. 11; S. 403.

15 VOLPI, F. Schopenhauer e a dialética, p. 108

16 Idem, p. 108-110.

17 Idem, p. 110

18 KANT, I. Crítica da razão pura, B 86.
} 
necessária para defendê-la e deve-se conhecer os estratagemas desonestos para poder enfrentá-los...". É assim que, em Schopenhauer, a dialética se impõe como o jogo do "ter razão", sem o ganho filosófico que Kant apontou em nome de uma razão iluminista que se limita a desentranhar antinomias cujas teses contraditórias, no fim das contas, se equilibram e se anulam mutuamente, tudo acabando afinal em "proposições falsas", sem peso nem valor.

Ora, o "ter razão" [Rechthaben] vai além do possuir a razão[Vernunft] como faculdade e a descrição da dialética erística pretende ir além do mero retraimento cognitivo da razão. A fim de mostrar como a "arte de ter razão" não se restringe ao nível da neutralização teórica promovida por Kant, vale a pena seguir de perto o acerto de contas de Schopenhauer com Aristóteles, que se sobressai no texto como o precursor daquilo que ele pretende ensinar.

\section{II}

No entender de Schopenhauer, Aristóteles "não define o objetivo da dialética de modo tão rigoroso" ${ }^{19}$ como ele pretende fazer. A falta de rigor na definição consistiria em que, embora tenha dado a disputa como finalidade principal da dialética, Aristóteles manteve "a descoberta da verdade"20 como um objetivo da dialética. Para Schopenhauer, a dialética ocorre no âmbito da mera disputa de opiniões e o critério de aprovação das mesmas não pode ultrapassar o limite da aparência da verdade. De acordo com o filósofo alemão, embora tenha tido consciência da distinção e da separação entre a "verdade objetiva de uma proposição" e a sua "validação ou a obtenção de aprovação", o mestre grego não soube mantê-las suficientemente separadas ${ }^{21}$.

Schopenhauer completa a crítica a Aristóteles dizendo que, embora sua exposição tenha sido metódica e sistemática, o objetivo manifestamente prático, não foi alcançado, e isso que faz com que "a utilidade prática" de sua dialética não seja grande $^{22}$. Schopenhauer salienta que, na dialética, Aristóteles passa a considerar o conteúdo daquelas formas de linguagem que ele analisa na analítica, o que o leva a lidar diretamente "apenas com conceitos", já que é neles que "reside a substância"

19 SCHOPENHAUER, A. A arte de ter razão, p. 6, VI 398.

20 Idem, ibidem.

21 Idem, p. 7, VI 398

22 Idem, p. 9, VI 402 
de todo discurso ${ }^{23}$. O estudo dos Tópicos seria, pois, o das "relações dos conceitos entre si", relações pelas quais se determinam a definição, o gênero, a particularidade, a característica essencial (o que é próprio) e o acidente da matéria relativa aos conceitos em questão. Essas relações conceituais dão lugar a regras gerais e por isso os "lugares" (loci, topoi) são explicitados como apresentações das "regras" para cada relação genérica possível dos conceitos entre $\mathrm{si}^{24}$. Schopenhauer menciona, por exemplo, o locus de causa e efeito: "A causa da causa é causa do efeito"; e também o locus da oposição: os opostos se excluem, por exemplo, o reto e o curvo. Ele salienta que os loci são "certas verdades genéricas", que atingem classes inteiras de conceitos, às quais se pode remontar a fim de "criar [zu schöpfen], a partir delas", os argumentos e também para invocá-las como "algo universalmente óbvio"25. É na medida em que os topoi são regras e verdades amplamente admitidas, que Aristóteles os considera como a fonte disponível da universalidade.

Contudo, diz Schopenhauer, esses topoi em geral, são bastante "enganosos" [trüglich] e estão submetidos a muitas exceções ${ }^{26}$. Ora, essa espécie de fragilidade da razão no campo da dialética também é apontada por Aristóteles quando ele adverte, ao longo dos Tópicos, sobre aqueles que são enganosos ou inúteis. A fim de ilustrar o caráter enganoso de um topos, Schopenhauer toma o seguinte exemplo: "As causas de todas as coisas contrárias entre si devem ser contrárias entre si; pois a razão proíbe que uma única e mesma causa tenha como efeito coisas diferentes e contrárias entre si"27. E emenda: "Muito bem! Mas a experientia docet que o calor que endurece a argila é o mesmo que amolece a cera, e uma centena de coisas semelhantes. E, no entanto, o topus soa plausível"28. O ponto é que a razão proíbe, mas a experiência ensina o contrário. Interessante notar que não se trata aqui de uma antinomia da própria razão, e sim de um conflito entre uma razão pura a priori e a experiência à qual ela deveria poder ser aplicada. No entender de Schopenhauer, pode-se até pensar que existam "verdades universalmente válidas", que seriam "aplicáveis a tudo" e pelas quais se poderia,

23 Idem, p. 7, VI 399

24 Idem, p. 8, VI 401.

25 Idem, p. 65 (nota 6), VI $428{ }^{* *} 9$ ).

26 Idem, ibidem.

27 Idem, p. 66 (nota 6), VI $428{ }^{(* *} 9$ ).

$28 \mathrm{Idem}$, ibidem.

A arte de ter razão 
portanto, "decidir todos os casos singulares, por mais heterogêneos que fossem"29. No entanto, ele considera isso impossível justamente porque os conceitos resultam de "abstrações de diferenças", e visam a compreender formalmente as coisas mais diversas.

Não se pode deixar de notar a tensão conceitual que a descrição schopenhaueriana enfatiza no conceito de topoi, que é central na dialética aristotélica: ele os caracteriza duplamente como "regras gerais" e "verdades gerais". Com isso, se faz notar com nitidez uma ambiguidade intrínseca ao próprio conceito de topos ou locus, que nos permite compreender melhor o caráter normativo dos mesmos e a justificativa de sua adoção como modelo de operação racional válida. Pois os topoi regulariam a inteligibilidade do uso dos conceitos e de suas relações, pelo enquadramento do discurso nos padrões normativos que eles exibem, e que se tornam os referenciais da racionalidade. Ora, até que ponto seguir uma regra é seguir uma verdade? E qual motivo nos leva a aceitar as regras gerais como verdades gerais? De todo modo, são essas verdades e regras gerais que seguimos, são estes os "lugares" de "onde" tiramos os nossos argumentos. Qual seria o estatuto dessas verdades se elas apenas instanciam regras que em geral são seguidas?

O ponto importante é: se uma verdade geral vale como uma regra geral, então, não pode se tratar de uma verdade "objetiva" no sentido estrito de ser correspondente aos fatos, mas sim a normas, isto é, regras que conferem sentido e inteligibilidade às argumentações. Isso bastaria para qualificá-las como simples convenções? Se assim fosse, o campo da dialética repousaria sobre a contingência dos acordos acerca dos topoi que se vinculam ao próprio uso das endoxa (e a relação interna entre ambos estes conceitos merece ser estudada). Ora, como se resolvem as coisas nesse campo de contingência dos acordos em Schopenhauer? Talvez sua resposta antecipe aspectos do que Nietzsche concebeu como o reino da "vontade de poder". Para justificar a linha desse pensamento, nada mais adequado do que tentar esmiuçar a proposta do autor do Mundo.

Como mostram os Adendos I e II da edição brasileira (que correspondem aos 29 Idem, p. 67 (nota 6), VI $428\left({ }^{\star *} 9\right)$ 
primeiros parágrafos do texto original consultado), Schopenhauer faz questão de definir sua dialética erística a partir da separação dos significados de lógica e dialética. A lógica é "a ciência das leis do pensamento", isto é, "do modo de proceder da razão" [Verfahrungsart der Vernunft], podendo dispor de seu objeto e ser construída de maneira puramente a priori, sem qualquer intervenção da experiência. Seu objeto são as leis que regulam o pensamento no procedimento da razão "deixada a si mesma" e não perturbada por nada nem ninguém que induza ao erro, o que ocorre "quando um ser racional pensa sozinho"30. É no mínimo curiosa essa íntima relação afirmada entre a forma pura e abstrata da razão e o seu êxito no pensamento solitário. De qualquer modo, os aspectos da razão em seu procedimento estritamente lógico são: o apriorismo, a pureza e a infalibilidade. A dialética, em contrapartida, envolve a comunhão de "dois seres racionais" que "pensam juntos" e que instauram uma disputa ou "batalha espiritual" tão logo deixem de concordar como "dois relógios sincronizados" - o que aconteceria se continuassem no domínio da pura razão. Como incorpora as divergências que nascem da diversidade que constitui a individualidade, que são, por definição, "elemento empírico", a dialética só pode ser construída a posteriori. Schopenhauer esclarece que a conversação dialética é "histórica", quando comunica fatos [Tatsachen], ou "deliberativa", quando comunica opiniões [Meinungen], e é no âmbito desta última, quando há divergência, que o ser humano se revela "prepotente por natureza" [von Natur rechthaberisch] e quer ter razão ${ }^{31}$. Ora, é sobre o que, neste contexto, leva alguém a ter razão que versará a disciplina schopenhaueriana da dialética erística.

É interessante notar que não há meio termo neste cenário descrito por Schopenhauer: ou há concordância mecânica na razão pura a priori - caso em que os indivíduos se harmonizariam como dois relógios sincronizados - ou há batalha espiritual entre individualidades divergentes. Como se verá a seguir, quanto ao uso polêmico da linguagem, o caráter da disputa se intensifica quando à vigência necessária de critérios subjetivos vem se somar certas disposições e inclinações da natureza humana. Os critérios são subjetivos precisamente porque, no entender de Schopenhauer, na dialética, o que importa não é obter a verdade, mas obter a razão: 
o que importa é a opinião "valer como" verdadeira, independentemente de ela ser ou não verdadeira. Como ele adverte, de fato, "é possível ter a razão objetiva na questão em si e, no entanto, aos olhos dos presentes, por vezes mesmo aos próprios olhos, não ter razão"32. Exatamente por isso, pode-se distinguir, com toda nitidez, "a verdade objetiva de uma proposição" e sua "validade na aprovação dos litigantes e ouvintes", sendo apenas a esta última que a dialética está direcionada ${ }^{33}$.

É óbvio que se o jogo é o do parecer ser verdadeiro, os critérios têm de ser limitados e a questão resolvida apenas com base na aprovação dos concernidos ao debate. Nesse terreno, pode-se até utilizar os padrões lógicos de correção da razão pura e abstrata, só que eles se revelam infrutíferos: sua aplicação gira em falso e não garante nenhuma determinação objetiva sobre a matéria indefinida dos discursos enraizados na empiria. É interessante notar que o padrão silogístico pode até ser seguido, mas no texto de Schopenhauer sobressai sempre a ênfase sobre uma matéria em relação a qual o aspecto formal da lógica não poderia dar conta.

Temos, então, critérios subjetivos e uma dialética nada pacificadora, pois não há nada que aponte para a geração espontânea de acordos: ou sincronia automatizada pela lógica formal ou o solo áspero da luta pela imposição do logos mais forte. A razão que se "quer ter" na arena social é a razão em conflito e a disciplina que deverá descrever seus métodos se confundirá com a "doutrina do modo de proceder pertencente à natural prepotência humana"34. Uma vez abandonada a região "sem perturbações" - o céu sublime - do pensamento puro, a conversação humana se institui como um duelo de forças em confronto, sem garantia de acordo racional (pela via da pura Vernunft), já que a tendência "não é reexaminar o próprio pensamento", mas "pressupor" que o "erro" esteja no pensamento do outro. Note-se que, embora mencione uma conversação de tipo "histórico", que envolveria a comunicação de fatos, é a conversação "deliberativa" justamente a que diz respeito à comunicação de opiniões - que fornece o modelo do conceito de dialética erística em Schopenhauer. Trata-se do contexto deliberativo cujas bases são as endoxa, só que apreendidas no regime do desacordo, da atribuição de erro aos outros e da incapacidade de autocrítica. O querer ter razão não só envolve um domínio que está além dos fatos, como se funda,

32 Idem, p. 3; VI 395

33 Idem, ibidem.

34 Idem, p. 60; VI 394. 
imperiosamente arraigado, nos traços inatos e adquiridos da natureza humana.

Para Schopenhauer, na origem de tudo está a "maldade natural do gênero humano"35, acompanhada da vaidade inata, da verbosidade e da desonestidade. E no terreno da conversação, o "interesse pela verdade" [Interesse für Wahrheit] cede cada vez mais espaço para o "interesse da vaidade" [Interesse der Eitelkeit], ao ponto de chegarmos na situação limite em que "o verdadeiro deve parecer falso, e o falso, verdadeiro"36. Sob tal ótica, a aparência [Schein] opera - não sozinha, mas por intenções movidas pela vontade - as inversões dos valores de verdade com o propósito claro de produzir o engano. Em Schopenhauer, a gramática da aparência não pode deixar de envolver as qualidades do caráter humano no qual se aliam "as fraquezas do nosso intelecto" e a "perversão de nossa vontade", que "apoiam-se reciprocamente" ${ }^{37}$. Intelecto e vontade: uma faculdade fraca unida a uma perversa. Essa pode ser a situação subjetiva de uma babel em plena guerra de todos contra todos, não obstante a orgulhosa posse da razão lógica abstrata. E o fato de que o que vale é a aparência de verdade e correção reforça cada vez mais a atitude de cada um "impor sua própria asserção, mesmo quando naquele instante ela lhe parecer falsa ou duvidosa"38. Ora, se a aparência geradora da incerteza se impõe ao sujeito a respeito de sua própria opinião, não há mesmo como ele confiar que a razão esteja do outro lado. Nesse sentido, é bastante sugestiva a menção a Maquiavel quando "prescreve ao príncipe que aproveite todo momento de fraqueza do seu vizinho para atacá-lo"39. O raciocínio é o seguinte: se dou razão ao adversário "tão logo ele parece tê-la, dificilmente ele fará o mesmo quando o caso se inverter". Ou seja: devo pressupor falta de lealdade e de honestidade no adversário, e dessa pressuposição (prevista nos estratagemas) vem a justificativa de que "tenho de fazer a mesma coisa"40. A fórmula seria: "Você é mau, portanto, devo sê-lo também". Tratase da recomendação de um comportamento normativo com base na concepção de certos traços da natureza humana quando se tem a linguagem como instrumento para organizar relações de poder. Tal como era para Maquiavel, tais relações que se pautam pela lógica da força, sem moral e sob o imperativo categórico de ter de

35 Idem, p. 3; VI 396

36 Idem, p. 4; VI 396.

37 Idem, p. 5; VI 397

$38 \mathrm{Idem}$, ibidem.

39 Idem, p. 62 (nota 3); VI $428\left({ }^{*} 4\right)$

$40 \mathrm{ldem}$, ibidem. 
vencer o logos mais forte: a figura do príncipe maquiaveliano vale como modelo de comportamento para a atuação do sujeito empírico em geral. É assim que a dialética, vista de um ponto de vista pragmático, abrange a "esperteza" [Schlauheit] que cada um também adquire na "experiência diária do ato de disputar". Ora, a esperteza e a maldade conformam a "dialética natural" que, no caso de Schopenhauer, pode faltar a muita gente, já que ela é "dom natural distribuído desigualmente" ${ }^{41}$.

Quando Schopenhauer exige que na dialética de Aristóteles se inclua também a sofística e a erística, para redefini-la como a arte de ter razão ao disputar, é inegável que ele lança ao escopo das opiniões geralmente aceitas um grau de incerteza que não se vê nos Tópicos, em que a imensa maioria dos topoi (das regras que permitem a criação de argumentos) encontram o abrigo de concepções filosóficas envolvendo a ontologia e a predicação aristotélicas - o que possibilita ao método dialético, em suas mãos, poder chegar, inclusive, à descoberta de princípios da ciência. Em relação a Kant, pode-se dizer que Schopenhauer confere à dialética um caráter mais pragmático: a razão que se disputa já não é mais só cognitiva, pois perfila o campo da racionalidade prática comandada pela vontade empírica. $\mathrm{O}$ estratagema 35 afirma claramente que "meia onça de vontade pesa mais do que uma tonelada de entendimento e convicção"42, especialmente em casos nos quais "o sentimento de cada um é uma regra"43. Esse estratagema, que, segundo Schopenhauer, torna dispensáveis todos os outros, é considerado o mais eficaz para se obter a razão porque em vez de "agir sobre o intelecto por meio de fundamentos", ele age "sobre a vontade por meio de motivações"44. Ora, há uma clara relação entre este estratagema e o de número 30 , no qual se expressa o ceticismo quanto à própria "autoridade" dos endoxa, pela consideração do modo arbitrário com que se formam, levando "ovelhas que seguem o carneiro-guia para onde quer que ele as conduza". Cético, o filósofo observa que as opiniões consideradas gerais ou universais, na verdade, são de "duas ou três pessoas" e tendem a ser aceitas sem nenhum julgamento, especialmente em contextos nos quais o consenso torna-se uma obrigação.

Para alguém "ter razão" [Rechthaben] não basta "ser racional", e nem precisa

41 Idem, p. 5; VI 397

42 Idem, p. 49; VI 425

43 Idem, p. 50; VI 425

44 Idem, p. 49; VI 425 
ter efetivamente a razão do seu lado. As tensões conceituais entre a verdade e regra, entre aparência como limite e aparência fabricada intencionalmente para enganar lembram muito certas discussões contemporâneas sobre o dogmatismo e o relativismo das crenças e valores que se instituem e se perpetuam sob a tutela única do uso da linguagem. Ilustremos isso com um fragmento do último Wittgenstein que, em Sobre a Certeza, escreve:

Eu disse que "combateria" o outro homem - mas lhe indicaria razões? Certamente; mas até onde é que chegam? No fim das razões vem a persuasão. (Pense no que acontece quando os missionários convertem os nativos) ${ }^{45}$.

Ora, não poderíamos dizer que, para Wittgenstein, em certo sentido, Schopenhauer "tem razão"?

\section{Referências bibliográficas}

ARISTÓTELES. Aristóteles. Obras Completas. Tópicos. Tradução, introdução e notas J. A. Segurado e Campos. Lisboa: Imprensa Nacional Casa da Moeda, 2007.

BERTI, Enrico. As razões de Aristóteles. Tradução Dion Davi Macedo. São Paulo: Edições Loyola. 1998.

KANT, Immanuel. Crítica da razão pura. Tradução Manuela P. dos Santos e Alexandre F. Morujão. Lisboa: Calouste Gulbenkian, 1994.

LEBRUN, Gérard. A dialética pacificadora. In: Marta Kawano, Maria Lúcia Cacciola e Carlos Alberto R. Moura (Orgs). A filosofia e sua história. São Paulo: Cosacnaify, 2006, pp. 89-127.

SALVIANO, Jarlee. O Novíssimo Organon: lógica e dialética em Schopenhauer. In: João Carlos Salles (Org.). Schopenhauer e o idealismo alemão. Salvador: Quarteto Editorial, pp. 99-113.

SCHOPENHAUER, Arthur. A arte de ter razão: exposta em 38 estratagemas. Organização e ensaio de Franco Volpi. Tradução Alexandre Krug e Eduardo Brandão. São Paulo: Martins Fontes, 2005.

. Eristische Dialektik. In: Schopenhauer in Kontext (Werke auf CD-ROM). Kap. Nr. 446, VI 393 - VI 428.

WITTGENSTEIN, Ludwig. Da certeza (edição bilíngue). Tradução de Maria Elisa Costa. Lisboa: Edições 70, 1990. 